\title{
Evaluation of Risk Factors for Second Hip Fractures in Elderly Patients
}

\author{
Sabri Batin ${ }^{\mathrm{a}, \mathrm{c}}$, Firat Ozan ${ }^{\mathrm{a}}$, Kaan Gurbuz ${ }^{\mathrm{a}}$, Semmi Koyuncu ${ }^{\mathrm{b}}$, \\ Fatih Vatansevera ${ }^{\text {, Erdal Uzun }}{ }^{\mathrm{a}}$
}

\begin{abstract}
Background: Hip fracture is a worldwide public health problem that primarily affects osteoporotic individuals and the elderly. A second hip fracture can occur in elderly patients who have already suffered an initial hip fracture. The aim of this study was to investigate possible risk factors for second hip fractures in elderly patients with hip fractures.
\end{abstract}

Methods: Between 2010 and 2014, 230 patients who underwent uncemented bipolar hemiarthroplasty for hip fractures were retrospectively analyzed. The patients were divided into two groups: those with a first hip fracture (group 1) and those with a second hip fracture (group 2).

Results: The mean time from the first hip fracture to second hip fracture was 22 months. There were no significant differences in the American Society of Anesthesiologist scores, comorbidities were observed in the two groups. The mean length of hospitalization was not significantly different between the two groups. The mean postoperative functional scores after second hip fractures were significantly lower in group 2 than in group 1.

Conclusions: Although there are not certain risk factors for second hip fractures in elderly patients with hip fractures, to prevent second hip fractures, elderly patients should be provided with physical and medical therapy as well as orthotic support and their functional activity should be maintained.

Keywords: Hip fracture; Hemiarthroplasty; Risk factors; Second hip fracture

\section{Introduction}

Hip fracture is a worldwide public health problem that pri-

Manuscript submitted December 3, 2017, accepted December 27, 2017

${ }^{a}$ Department of Orthopedics and Traumatology, Kayseri Training and Research Hospital, Kayseri, Turkey

bepartment of Orthopedics and Traumatology, Bayburt State Hospital, Bayburt, Turkey

${ }^{\mathrm{C} C}$ Corresponding Author: Sabri Batin, Department of Orthopedics and Traumatology, Kayseri Training and Research Hospital, Sanayi Mah. Ataturk Bulvari, Hastane Cad. 38010 Kocasinan, Kayseri, Turkey.

Email: dr.ortopedi@hotmail.com

doi: https://doi.org/10.14740/jocmr3287w marily affects osteoporotic individuals and the elderly [1-6]. Systemic conditions are common in the elderly $[1,6]$. Such conditions, which increase with age, can lead to fragmented fractures of the proximal femur or unstable fractures caused by minor injuries and are considered one of the leading causes of death in elderly people $[1,7,8]$.

A second hip fracture reportedly occurs in $2-10 \%$ of elderly patients who have already suffered an initial hip fracture [3, $6,9-11]$. The risk factors for first hip fractures have been well established in previous studies [5,6]. Several authors have also attempted to define the possible risk factors for second hip fractures, with osteoporosis and comorbidities suggested to be the primary factors. In addition, compared with the first hip fractures, second hip fractures are associated with high rates of postoperative complication and socioeconomic burden [12, 13]. Therefore, a better understanding of the possible risk factors for second hip fractures is important for preventing such cases in the elderly [7].

In this study, we aimed to investigate possible risk factors for second hip fractures in elderly patients with hip fractures.

\section{Materials and Methods}

Between 2010 and 2014, 230 patients (121 females and 109 males; 132 right hips and 117 left hips; 19 bilateral hips; mean age: 73.36 years; age range: 65 - 91 years) who underwent uncemented bipolar hemiarthroplasty for proximal femoral fractures were retrospectively analyzed. The patients were divided into two groups: those with a first hip fracture (group 1: 110 females and 101 males; 113 right hips and 98 left hips) and those with a second hip fracture (group 2: 10 females and nine males; 19 right hips and 19 left hips) (Fig. 1).

The exclusion criteria were as follows: pathological fractures or high-energy fractures, concomitant bilateral hip fractures, primary hip fractures or hip fractures secondary to a tumour lesion and metabolic bone disease.

The age and sex of the patients, type of fracture, the American Society of Anesthesiologist (ASA) scores [14], Singh index (SI) [15], time from the hip fracture to surgery, length of hospitalization, and comorbidities were recorded. The University of California, Los Angeles (UCLA) hip scoring [16] assessment was used to evaluate patients' postoperative functional results. The presence of associated comorbidities including cancer, renal diseases and neurological/cardiac/pulmonary/ endocrinological conditions was examined.

This study was conducted in accordance with the princi- 




Figure 1. (a) Radiographic image of the left femoral neck fracture treated with hip hemiarthroplasty in a 74-year-old male. After 2 months postoperatively, femoral neck fracture has developed on the right side and (b) hip hemiarthroplasty was performed.

ples of the Declaration of Helsinki and informed consent was obtained from each patient.

\section{Statistical analysis}

Statistical analysis was performed using PASW version 18.0 software (SPSS Inc., Chicago, IL, USA). Frequency analysis was performed for categorical variables. The data were expressed as numbers and percentages. The paired Student's $t$ tests and Pearson's Chi-square tests were used to compare categorical data. $\mathrm{P}<0.05$ was considered statistically significant.

\section{Results}

There were no significant differences between groups 1 and 2 in terms of sex and fracture type (sex: $\chi^{2}=0.460, \mathrm{P}=0.498$; fracture type: $\chi^{2}=6.59, \mathrm{P}=1.99$ ). Fracture distributions of the patients were classified according to the AO/OTA classification as follows: in group 1, B1 in 131 patients $(62 \%), \mathrm{B} 2$ in 32 $(15.1 \%)$ and $\mathrm{B} 3$ in 48 (22.7\%); in group 2, B1 in 12 patients
(63.1\%), B2 in four $(21 \%)$ and B3 in three (15.7\%).

The mean follow-up was 18.3 (range: 6 - 30) months. The mean age of the patients in groups 1 and 2 was 79.2 (range: 65 $102)$ and 81.3 (range: 70 - 94) years, respectively $(\mathrm{P}=0.0068)$. The mean ASA scores were 2.88 (range: $1-4$ ) in group 1 and 2.84 (range: 2 - 4) in group 2: there was no significant difference between the groups $(P=0.2871)$ (Table 1$)$. In group 2 , the mean time from the first hip fracture to the second hip fracture was 22.7 months (range: 2 - 68 months). The mean SI in groups 1 and 2 was 2.60 (range: 1 - 5) and 2.42 (range: 1 - 4), respectively $(\mathrm{P}=0.138)$. The SI was categorized into two degrees, namely $1-3$ and 4 - 6. Moreover, these subcategories did not differ significantly between the two groups $\left(\chi^{2}=0.540, \mathrm{P}=0.463\right)$.

The comorbidities observed in the two groups were not significantly different (neurological: $\chi^{2}=0.440, \mathrm{P}=0.614$; cardiac: $\chi^{2}=4.55, \mathrm{P}=0.54$; pulmonary: $\chi^{2}=1.272, \mathrm{P}=0.259$; endocrinological: $\left.\chi^{2}=0.652, \mathrm{P}=0.419\right)($ Table 2).

In groups 1 and 2 , the mean time from the first hip fracture to surgery was 1.64 (range: 1 - 11) and 1.16 (range: 0 - 6) days, respectively $(\mathrm{P}=0.1750)$. The mean duration of surgery was $71.9 \mathrm{~min}$ in group 1 and $72.63 \mathrm{~min}$ in group $2(\mathrm{P}=0.5184)$.

The mean length of hospitalization, which was 8.99

Table 1. Demographic Characteristics and Clinical Outcomes

\begin{tabular}{|c|c|c|c|}
\hline & Group $1(n=211)$ & Group $2(n=19)$ & P value \\
\hline Mean age, years (range) & $79.2(65-102)$ & $81.3(70-94)$ & 0.0068 \\
\hline \multicolumn{4}{|l|}{ Sex, n (\%) } \\
\hline Male & $101(47.9)$ & $9(47.4)$ & \\
\hline Mean ASA score & 2.88 & 2.84 & 0.2871 \\
\hline $1-3$ & $97(45.9)$ & $11(57.8)$ & 0.463 \\
\hline $4-6$ & $114(54.1)$ & $8(42.2)$ & \\
\hline Time from fracture to surgery, days (range) & $1.64(0-11)$ & $1.16(0-6)$ & 0.1750 \\
\hline Mean duration of surgery, min & 71.9 & 72.63 & 0.5184 \\
\hline Mean length of hospitalisation, days & 8.99 & 7.11 & 0.422 \\
\hline
\end{tabular}

ASA: American Society of Anesthesiologists; SI: Singh index; UCLA: University of California-Los Angeles. 
Table 2. Comparison of Comorbidities in Groups 1 and 2

\begin{tabular}{|c|c|c|c|c|c|}
\hline & & $(n=211)$ & & $2(n=19)$ & \\
\hline & n & $\%$ & $\mathbf{n}$ & $\%$ & I vaiue \\
\hline Cardiac diseases & 131 & 62.0 & 15 & 78.9 & 0.54 \\
\hline Pulmonary diseases & 41 & 19.4 & 3 & 15.7 & 0.259 \\
\hline Endocrinological diseases & 66 & 31.2 & 9 & 47.3 & 0.419 \\
\hline
\end{tabular}

(range: 3 - 24) and 7.11 (range: 3 - 14) days in groups 1 and 2, respectively, was not significantly different between the two groups $(\mathrm{P}=0.422)$. The mean postoperative UCLA scores after second hip fractures were significantly lower in group 2 than in group $1(\mathrm{P}=0.0097)$.

\section{Discussion}

We found that the postoperative functional results were significantly lower following second hip fractures. This result can be attributed to the fact that a second injury may increase the possibility of being confined to bed and receiving familial support. Therefore, rehabilitation is essential for patients with second hip fractures in order to ensure that they regain mobility. Although patients usually make a substantial effort to regain functionality and walking ability following hip surgery, reduced ambulatory skills and inadequate adaptation to the rehabilitation program after the first hip fracture may contribute to the occurrence of a second hip fracture.

Hip fractures affect elderly people worldwide and represent a global public health issue $[1,2]$. Unstable proximal femoral fractures may result from low-energy fractures caused by the increased prevalence of osteoporosis and falls in the elderly $[1,2,8]$. All fractures represent a significant cause of morbidity and reduced quality of life, and they are also associated with increased mortality rates $[1,2,17]$. In the elderly patient population, the mortality rate within the first year after a first hip fracture is $10-20 \%[1,2,5]$.

Along with comorbidities and osteoporosis, being confined to the bed following a first hip fracture may increase the risk of suffering a second hip fracture $[5,6,13]$. Yamanashi et al [4] reported that a total of 29 out of 1,000 patients suffered a second hip fracture within the first year of their first hip fractures. Similarly, Hagino et al [3] reported the rate of second hip fractures as 3.4\% and Mitani et al [7] reported the rate as $4.3 \%$ in their study cohort. The most risky period for second hip fractures is the first year after the first hip fracture and the risk gradually reduces thereafter [9, 13]. Half of second hip fractures occur within the first 2 years of a first fracture, whereas $70 \%$ occur within the first 3 years $[3,10]$. In this study, 19 patients had the second hip fracture among 230 hip fracture patients, the rate is approximately $8 \%$, which is consistent with previous studies. We also found that $47.3 \%$ of second hip fractures occurred within the first year following the first hip fracture.

Several epidemiological studies have demonstrated that second hip fractures are associated with various risk factors such as neurological diseases, falls, reduced perceived health status, low body weight, physical inactivity, dizziness and osteomalacia [5-7, 9-11, 13]. Yamanashi et al [4] also showed that senile dementia and Parkinson's disease were major risk factors for second hip fractures. In a case-control study, Saxena and Shankar [10] demonstrated that second hip fractures were significantly associated with cerebrovascular accidents, Alzheimer's disease, syncope and blindness. In another study, Mitani et al [7] found that second hip fractures were associated with pulmonary diseases. Angthong et al [13] demonstrated that patients with ophthalmological conditions also had a high risk of suffering second hip fractures. The authors reported that such conditions reduced walking ability and thereby increased the patient's risk of falls.

In contrast to other studies, Lonnroos et al [18] found no significant association between comorbidities and second hip fractures. Similarly, we found that no comorbidities were significantly associated with second hip fractures.

The SI is used to define various processes of increasing losses of the trabecular structures due to disease progression. However, some reports suggest that the SI is of minimal value when predicting hip fractures [19]. Yamanashi et al [4] showed no significant difference in the SI among patients with first and second hip fractures. On the other hand, in their prospective study, Gluer [20] reported that a low SI was a risk factor for hip fracture. Unlike these findings, we found that SI did not differ significantly between the patient groups. In addition, we classified the SI into two degrees, namely 1 - 3 and 4 - 6: we found no significant differences in the subcategories observed in groups 1 and 2 .

Age and female gender may be important risk factors for hip fractures $[6,21,22]$. However, age and sex do not differ in patients with unilateral and bilateral hip fractures [4, 11, 23]. In a systematic review, Egan et al [6] reported that female gender was not a consistent risk factor for subsequent hip fractures following the first fractures, and they indicated that men and women may be at similar risk of suffering second hip fractures. Dretakis et al [11] demonstrated that a higher number of patients with second hip fractures were older with reduced mobility, and they postulated that a progressive decrease in bone mass might cause more unstable second fractures. In our study, we found no significant difference between the groups in terms 
of the type of fracture and sex; however, the patients in group 2 were found to be significantly older than in group 1.

We note that this study has some limitations. These include its retrospective design and small sample size. In addition, we did not examine the association between second hip fractures and familial factors, social factors or pharmaceutical preparations. Nonetheless, we believe that our study provides further understanding of the possible risk factors associated with second hip fractures in the elderly.

In conclusion, although there are not certain risk factors for second hip fractures in elderly patients with hip fractures, functional activity should be maintained in elderly hip fracture patients, and physical therapy, medical therapy and orthotic support should be provided. In addition, high-risk patients should be identified and preventive strategies should be developed for this patient population as a part of orthopedic support.

\section{Competing Interests}

The authors declare that they have no competing interests.

\section{Grant Support}

None.

\section{Financial Disclosure}

None.

\section{References}

1. Pugely AJ, Martin CT, Gao Y, Klocke NF, Callaghan JJ, Marsh JL. A risk calculator for short-term morbidity and mortality after hip fracture surgery. J Orthop Trauma. 2014;28(2):63-69.

2. Ciarelli TE, Fyhrie DP, Schaffler MB, Goldstein SA. Variations in three-dimensional cancellous bone architecture of the proximal femur in female hip fractures and in controls. J Bone Miner Res. 2000;15(1):32-40.

3. Hagino H, Sawaguchi T, Endo N, Ito Y, Nakano T, Watanabe Y. The risk of a second hip fracture in patients after their first hip fracture. Calcif Tissue Int. 2012;90(1):1421.

4. Yamanashi A, Yamazaki K, Kanamori M, Mochizuki K, Okamoto S, Koide Y, Kin K, et al. Assessment of risk factors for second hip fractures in Japanese elderly. Osteoporos Int. 2005;16(10):1239-1246.

5. Chapurlat RD, Bauer DC, Nevitt M, Stone K, Cummings $\mathrm{SR}$. Incidence and risk factors for a second hip fracture in elderly women. The Study of Osteoporotic Fractures. Osteoporos Int. 2003;14(2):130-136.

6. Egan M, Jaglal S, Byrne K, Wells J, Stolee P. Factors associated with a second hip fracture: a systematic review. Clin Rehabil. 2008;22(3):272-282.
7. Mitani S, Shimizu M, Abo M, Hagino H, Kurozawa Y. Risk factors for second hip fractures among elderly patients. J Orthop Sci. 2010;15(2):192-197.

8. Ozan F, Koyuncu S, Pekedis M, Altay T, Yildiz H, Toker G. Greater trochanteric fixation using a cable system for partial hip arthroplasty: a clinical and finite element analysis. Biomed Res Int. 2014;2014:931537.

9. Chang JD, Yoo JH, Reddy P, Lee SS, Hwang JH, Kim TY. Risk factors for contra-lateral hip fracture in elderly patients with previous hip fracture. Injury. 2013;44(12):1930-1933.

10. Saxena P, Shankar J. Contralateral hip fractures - can predisposing factors be determined? Injury. 2000;31(6):421424.

11. Dretakis KE, Dretakis EK, Papakitsou EF, Psarakis S, Steriopoulos K. Possible predisposing factors for the second hip fracture. Calcif Tissue Int. 1998;62(4):366-369.

12. Fukushima T, Sudo A, Uchida A. Bilateral hip fractures. J Orthop Sci. 2006;11(5):435-438.

13. Angthong C, Suntharapa T, Harnroongroj T. [Major risk factors for the second contralateral hip fracture in the elderly]. Acta Orthop Traumatol Turc. 2009;43(3):193-198.

14. Owens WD, Felts JA, Spitznagel EL, Jr. ASA physical status classifications: a study of consistency of ratings. Anesthesiology. 1978;49(4):239-243.

15. Singh M, Nagrath AR, Maini PS. Changes in trabecular pattern of the upper end of the femur as an index of osteoporosis. J Bone Joint Surg Am. 1970;52(3):457-467.

16. Naal FD, Impellizzeri FM, Leunig M. Which is the best activity rating scale for patients undergoing total joint arthroplasty? Clin Orthop Relat Res. 2009;467(4):958-965.

17. Malgo F, Hamdy NA, Papapoulos SE, Appelman-Dijkstra NM. Bone material strength as measured by microindentation in vivo is decreased in patients with fragility fractures independently of bone mineral density. J Clin Endocrinol Metab. 2015;100(5):2039-2045.

18. Lonnroos E, Kautiainen H, Karppi P, Hartikainen S, Kiviranta I, Sulkava R. Incidence of second hip fractures. A population-based study. Osteoporos Int. 2007;18(9):12791285.

19. Heneghan JP, Kirke PN, Murphy BL, Darcy E, Daly L, Bourke GJ, Dinn E, et al. Evaluation of quantitative CT vertebral bone mineral density measurement and the Singh index in elderly females with hip fractures - a case control study. Br J Radiol. 1997;70(837):923-928.

20. Gluer CC, Cummings SR, Pressman A, Li J, Gluer K, Faulkner KG, Grampp S, et al. Prediction of hip fractures from pelvic radiographs: the study of osteoporotic fractures. The Study of Osteoporotic Fractures Research Group. J Bone Miner Res. 1994;9(5):671-677.

21. Cummings SR. Treatable and untreatable risk factors for hip fracture. Bone. 1996;18(3 Suppl):165S-167S.

22. Hinton RY, Lennox DW, Ebert FR, Jacobsen SJ, Smith GS. Relative rates of fracture of the hip in the United States. Geographic, sex, and age variations. J Bone Joint Surg Am. 1995;77(5):695-702.

23. Finsen V, Benum P. The second hip fracture. An epidemiologic study. Acta Orthop Scand. 1986;57(5):431-433. 